\title{
O DIÁRIO DE REGISTROS COMO INSTRUMENTO DE (TRANS)FORMAÇÃO DOCENTE
}

\author{
Ana Lúcia Souza de Freitas ${ }^{1}$; Maria Elisabete Machado $^{2}$; Micheli Silveira de Souza ${ }^{3}$
}

\begin{abstract}
RESUMO
Transformar as relações de ensinar e aprender, na perspectiva de superar "práticas bancárias" é um tema relevante no campo da (trans)formação docente. Neste trabalho, as pesquisadoras compartilham a proposição do diário de registros como instrumento de apoio às práticas crítico-reflexivas. Com base em suas experiências de ensino e pesquisa, buscam responder um questionamento recorrente: "afinal, como fazer?". Para tanto, realizam análise documental revisitando produções acadêmicas anteriores, bem como seus próprios diários de registros. Resulta desta análise uma compreensão não prescritiva sobre o "como fazer", identificando quatro momentos constitutivos, também compreendidos como um processo de (trans)formação docente: o convite; os primeiros registros; a mediação do processo; e a avaliação da experiência. Espera-se que esta sistematização contribua para orientar a recriação da experiência do diário de registros em outros contextos de ensino-pesquisa.
\end{abstract}

Palavras-chave: Educação bancária; Diário de registros; (Trans)formação docente.

\begin{abstract}
Changing the teaching and learning relationship in order to overcome the "banking practices" is a relevant subject in the teaching (trans) formation field. In this work, the researchers share the proposition of the register diary as supporting instrument of the critical-reflexive practices. Based on their teaching and researching experience, they pursue to answer a frequent questioning: "After all, How to do it? To answer this questioning they carried out a documental analysis revisiting previous academic works as well as their own research diaries. After this analysis, they came up with a non-prescriptive comprehension on "how to do it", identifying four constitutive moments also understood as a process of teaching (Trans) formation: the invitation, the first registers, the mediation of the process; the evaluation of the experience. They expect this systematization can contribute to guide the recreation of the diary experience in other contexts of teaching-research.
\end{abstract}

Keywords: Banking education, Register diary, Teaching (trans)formation

\section{RESUMEN}

Transformar las relaciones de enseñar y aprender, en la perspectiva de superar las "concepciones bancarias" es un tema notable en el campo de la (trans)formación docente. En este trabajo, las

${ }^{1}$ Doutora em Educação (PUCRS), com pós-doutorado em Pedagogia Crítica (Liverpool Hope University); professora e pesquisadora no Mestrado Profissional em Gestão Educacional (MPGE) da Universidade do Vale do Rio dos Sinos (UNISINOS); Líder do Grupo de Pesquisa Formação de Professores e de Gestores e Práticas Pedagógicas. anafr@unisinos.br

2 Doutoranda em Educação na Pontifícia Universidade Católica do Rio Grande do Sul (PUCRS). Intregante do Grupo de Pesquisa Formação de Professores e de Gestores e Práticas Pedagógicas. mmelisabete@yahoo.com.br

3 Graduada em Pedagogia pela Pontifícia Universidade Católica do Rio Grande do Sul (PUCRS); Professora dos anos iniciais do Ensino Fundamental na Rede Municipal de Canoas. Intregante do Grupo de Pesquisa Formação de Professores e de Gestores e Práticas Pedagógicas. micheli.souza@acad.pucrs.br 


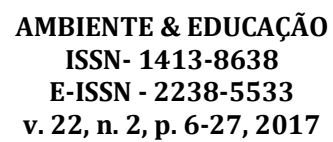

investigadoras compartirán la propuesta del diario de registros como instrumento de apoyo a las prácticas crítico-reflexivas. Basadas en sus experiencias de enseñanza e investigación, buscan contestar a una discusión recurrente: “al final, ¿cómo hacerlo?”. Para eso, realizan análisis documentales revisitando producciones académicas anteriores, así como sus propios diarios de registros. Resulta de este análisis una comprensión no prescriptiva sobre "cómo hacerlo", identificando cuatro momentos constitutivos, también comprendidos como un proceso de (trans)formación docente: la invitación; los primeros registros; la mediación del proceso; y la evaluación de la experiencia. Se espera que esta sistematización contribuya para orientar la recreación de la experiencia del diario de registros en otros contextos de enseñanza/investigación.

Palabras claves: Educación bancaria, diario de registros; (trans)formación docente.

\section{INTRODUÇÃO}

"O "método" foi só a botina que calçaram nos pés para caminhar.
Muita gente, de tanto haver o olhado só as marcas dela no caminho,
pensou que aquilo fosse toda a prática" (BRANDÃO, 1981, p.15).

Transformar a qualidade das relações de ensinar e aprender, na perspectiva de superar "práticas bancárias" é um tema relevante no campo da (trans)formação docente, sendo esta uma perspectiva que se alinha à atualidade desafios político-pedagógicos na formação de educadores ambientais no ensino superior, na perspectiva do que propõe Dickmann (2017) acerca de uma pedagogia da (in)disciplina ambiental. Tomando como referência, entre outros, o pensamento de Paulo Freire, o autor apresenta algumas considerações acerca do "que fazer" na escola, nas licenciaturas e na pós-graduação, tendo em vista pensar a educação ambiental como uma contribuição para a formação crítica de educadores/as em geral, entre elas:

Tornar a escola um espaço de formação permanente, de formação na ação, pela práxis (ação-reflexão-ação), no diálogo problematizador sobre o entorno comunitário (temas geradores), do contexto concreto (situações-limites), projetando as ações transformadoras (atos-limites) para a superação da realidade desumanizadora em vista da construção de uma sociedade sustentável para a humanização de todos (inédito viável) (DICKMANN, 2017, p.67).

A proposição deste artigo, ainda que não seja oriunda de contextos de formação de educadores ambientais, alinha-se ao pensamento do autor no que se refere à concepção de educação, com base no pensamento freireano, como forma de intervenção no mundo (FREIRE, 1996) e, portanto, de pensar a docência como uma prática socialmente referenciada, que requer o exercício da criticidade, da curiosidade e da criatividade de educadores/as e educandos (FREITAS, 2001). É nesta perspectiva que se considera a prática educativa como um processo de (trans)formação permanente, o qual requer 
instrumentos e procedimentos para apoiar a reflexão e investigação sobre a prática no sentido de maximizar o potencial emancipatório das relações de ensinar e de aprender.

Compreende-se por (trans)formação os processos pessoais e singulares que constituem a identidade profissional docente, na intersecção entre a formação profissional e o processo global de formação pessoal (MOITA, 1992). Diante da multiplicidade de fatores envolvidos, a experiência de reflexão sobre a prática, ao levar em conta sua historicidade e as características dos contextos institucionais, constitui-se importante componente de (trans)formação docente.

No âmbito desta discussão, importa considerar as abordagens de ensino que fundamentam as práticas docentes e que, com diferentes ênfases, apresentam proposições para superar a abordagem tradicional do ensino (MIZUKAMI, 2012), denominada por Paulo Freire de "educação bancária" (FREIRE, 1987). A referida metáfora, empregada pelo autor, é amplamente difundida para fazer referência à necessidade de transformar relações de subordinação acrítica dos educandos, nas quais a práticas educativas "se assentam na narração alienada e alienante" (SARTORI, 2010, p.135); em outras palavras, restringem o ato de ensinar à explicação do/a professor/a como centralidade do processo de conhecimento que se realiza com os educandos.

Transformar as práticas marcadas pela concepção bancária da educação é um objetivo que vem sendo perseguido pelas autoras em seus percursos individuais, bem como nas diferentes interfaces que os aproximaram, especialmente nas experiências de articulação universidade escola. Entre outras, a participação, em anos anteriores, no Programa Institucional de Bolsas de Iniciação à Docência (PIBID) e, atualmente, em um grupo de pesquisa vinculado a um Programa de Mestrado Profissional em Gestão Educacional, vêm fortalecendo as relações pessoais e institucionais em seus percursos de (trans)formação docente. Assim, entre interfaces e autorias, o percurso delineado vem evidenciando o potencial do diálogo que se problematiza em função da diversidade dos momentos de suas experiências acadêmicas: uma pós-doutora em educação, atualmente professora e pesquisadora em um curso de Mestrado Profissional; uma doutoranda em um programa de pós-graduação em educação e uma graduada no Curso de Pedagogia, professora dos anos iniciais do Ensino Fundamental em uma rede municipal de ensino. 
Importa referir que as coautoras, tendo participado da experiência de elaboração do diário, inicialmente como estudantes, tomaram para si o desafio de recriá-la em suas experiências como professoras-pesquisadoras. Além disso, tomaram a própria experiência como objeto de estudo no percurso de sua formação acadêmica: uma em função da realização do Curso de Mestrado em Educação e outra, no Trabalho de Conclusão de Curso (TCC) na Graduação em Pedagogia.

Na dissertação de Machado (2012), intitulada Diálogos em roda: uma práxis pedagógica possível com a educação formal e não formal, o diário se efetivou como um instrumento de diálogo da professora alfabetizadora com estudantes dos anos iniciais. Sua pesquisa evidenciou o potencial (trans)formativo do diário no que diz respeito ao sucesso das aprendizagens de sujeitos anteriormente desacreditados, resultando na compreensão de que "os diálogos em roda, com o apoio do diário de pesquisa, contribuem para minimizar a distância nas relações que se estabelecem entre educador e educandos e para fortalecer as aprendizagens" (MACHADO, 2012, p.8). Também permitiu perceber o valor das relações de confiança produzidas entre educadora e educandos, por meio do diário, concluindo que "a práxis dialógica exercida com a aprendizagem da confiança potencializou a mudança de visão de si como sujeito aprendiz. A aprendizagem da confiança denunciou as situações de opressão e anunciou possibilidades de ser mais" (op. cit., p.72).

A pesquisa de Machado orientou-se pelo princípio da articulação universidade escola, constituindo-se a partir de três momentos distintos e complementares: a aprendizagem acadêmica do diário; a recriação da experiência com o diário na escola; a experiência da escola como conteúdo na formação acadêmica. Assim, na continuidade da experiência entre as pesquisadoras, a partir da finalização da pesquisa, os resultados do trabalho na escola também contribuíram para atribuir sentido e significado à aprendizagem do diário como conteúdo da formação acadêmica.

No TCC de Souza (2014), intitulado O diário de pesquisa na formação do educador pesquisador: a experiência do PIBID/Pedagogia, os diários coletivos elaborados no contexto do trabalho do Programa Institucional de Bolsas de Iniciação à Docência (PIBID) foram objetos de análise, contribuindo para compreender os benefícios do uso sistemático do diário, transformado em instrumento coletivo. A este respeito, foram observados alguns resultados: “o enriquecimento de memórias do grupo; 
um espírito de pesquisa e, como consequência, o investimento em produções acadêmicas para participação em eventos na área da educação, o que contribui para a formação do educador pesquisador" (SOUZA, 2014, p.7).

$\mathrm{Na}$ continuidade da experiência entre as pesquisadoras, a partir da finalização da pesquisa, os resultados contribuíram para consolidar a compreensão acerca do potencial formativo do diário para a pesquisa sobre a própria prática, tendo em vista sua transformação, mas também para incentivar a produção acadêmica dos/as educadores/as que atuam na escola. A pesquisa igualmente contribuiu para visibilizar o diário coletivo como uma alternativa para encorajar a escrita individual.

Os referidos percursos de (trans)formação compartilham a ousadia, no âmbito da pesquisa acadêmica, em trilhar percursos metodológicos inédito-viáveis (FREIRE, 2010), assumindo o desafio de tomar a própria experiência como objeto de investigação. A experiência do diário com crianças em processo de alfabetização e a criação do diário coletivo com o PIBID são referências para pensar possibilidades de recriação da proposição do diário de registros em diferentes contextos, sem perder de vista a intencionalidade que lhe é fundante: transformar as relações bancárias nos processos de ensinar e de aprender, fomentando o desenvolvimento de práticas críticas-reflexivas (ALARCÃO, 2001).

Realizar procedimentos metodológicos inédito-viáveis, na compreensão das autoras, significa assumir o risco de propor o novo em função do compromisso com a transformação dos limites percebidos nas práticas convencionais. Ou seja, trata-se de assumir a natureza utópica da prática educativa, no âmbito do ensino, da pesquisa, e das relações entre eles. Como concebe Ana Maria Freire, o inédito-viável

\footnotetext{
[...] não é uma simples junção de letras ou uma expressão idiomática sem sentido. É uma palavra na acepção freireana mais rigorosa. Uma palavraação, portanto práxis. Uma palavra epistemologicamente construída para expressar, com enorme carga afetiva, cognitiva, política, ética e ontológica, os projetos e os atos das possibilidades humanas. Uma palavra que traz nela mesma o germe das transformações possíveis voltadas para um futuro mais humano e ético. [...] Palavra na qual estão intrínsecos o dever e o gosto, como gostava de dizer Paulo, de mudarmos a nós mesmos dialeticamente mudando o mundo e sendo por esse mudado (2000, p.15).
}

É nesta perspectiva da produção do inédito-viável, como um processo sempre inconcluso e desafiador, que se complementam os resultados obtidos pelas autoras em diferentes momentos de seus percursos acadêmicos. Uma tese de doutorado em 
educação (FREITAS, 2004), uma dissertação de mestrado em educação (MACHADO, 2012) e um trabalho de conclusão de curso de graduação em Pedagogia (SOUZA, 2014) fundamentam a proposição que hoje se apresenta acerca do diário de registros como um instrumento de (trans)formação docente que problematiza as relações de ensinar e de aprender e se realiza como instrumento de diálogo entre educadores/as e educandos.

No percurso delineado até o momento, percebe-se que as experiências como o diário de registros no âmbito do ensino, em diferentes contextos, deflagram processos de (trans)formação das relações de ensinar e de aprender, ampliando as condições para o diálogo entre educador/a e educandos. Processos de (trans)formação que tanto vêm proporcionando o desenvolvimento de práticas crítico-reflexivas, quanto vêm produzindo dados para a investigação sobre o ensino a partir da documentação da experiência. Deste modo, as experiências de ensino compartilhadas pelas autoras e sistematizadas por meio da produção acadêmica vêm contribuindo para produzir novas compreensões acerca do potencial (trans)formador das relações entre ensino e pesquisa e para consolidar a proposição acerca do diário de registro como instrumento de (trans)formação docente.

Mas “afinal, como fazer?”, é um questionamento que se fez recorrente no percurso de produção da proposição que hoje se apresenta. Buscando identificar os momentos constitutivos do processo de (trans)formação em que o diário de registros se realiza como instrumento de diálogo entre educadores/as e educandos, as autoras revisitaram produções acadêmicas anteriores, bem como seus próprios diários de registros. O objetivo do estudo realizado foi o de sistematizar uma orientação não prescritiva sobre "como fazer", de modo a apoiar a experiência de ensino-pesquisa por meio do diário de registros.

$\mathrm{Na}$ continuidade, o texto se organiza em quatro partes para compartilhar a compreensão proporcionada pelo estudo realizado. Inicialmente, apresenta a fundamentação em que se assenta a proposição do diário de registros como um instrumento de ensino-pesquisa. A seguir, apresenta os caminhos metodológicos que permitiram identificar momentos constitutivos do processo de elaboração do diário no âmbito do ensino, compreendido como um processo de (trans)formação docente e também discente. Na terceira parte, apresenta uma sistematização sobre o "como fazer", resultante da análise realizada, apresentando quatro momentos complementares: o 
convite; os primeiros registros; a mediação do processo; e avaliação da experiência. Cada momento é caracterizado a partir de questionamentos que o integram, a fim de orientar a proposição de ações de modo não prescritivo, mas, inversamente, desafiar novas autorias. Ao final, apresentam-se ainda algumas considerações para seguir a experiência de ensino-pesquisa, buscando maximizar o potencial (trans)formador do percurso de elaboração do diário de registros, na perspectiva da constituição de educadores/as pesquisadores/as.

\section{O DIÁRIO DE REGISTRO COMO INSTRUMENTO DE ARTICULAÇÃO ENSINO-PESQUISA}

O diário vem sendo reconhecido como um instrumento da pesquisa de natureza qualitativa, visibilizando e credibilizando as vozes dos/as educadores/as por meio da escrita narrativa. Também se reconhece, no uso deste instrumento, a função formativa da escrita no processo de ensino e suas relações com a pesquisa. Entre outros, destacamse no âmbito da formação de professores as produções de Zabalza (2004), com os diários de aula, e Barbosa (2010), com o diário de pesquisa.

Miguel Zabalza, ao referir as possibilidades de uso do diário como instrumento de formação continuada, apresenta quatro âmbitos de impacto formativo dos diários: desenvolvimento profissional, acesso ao mundo pessoal, explicitação dos próprios dilemas e avaliação e reajuste de processos. Joaquim Gonçalves Barbosa, com base em Hemi Hess, propõe o diário de pesquisa para a formação do estudante universitário, concebendo-o como um recurso processual de autoformação para a pesquisa, para a escrita e para a formação de si como autor/a.

Em consonância com os autores, o diário de registros se realiza como um instrumento de (trans)formação das relações de ensinar e de aprender, incentivando a cultura da pesquisa no ensino. Por outro lado, diferencia-se por não ter ênfase na escrita narrativa, nem a intenção de identificar tipologias, tal como propõe Zabalza que, mesmo ao considerar que "os diários podem variar tanto pelo conteúdo que recolhem como pela periodicidade com que são escritos e pela função que cumprem" (ZABALZA, 2004, p.15), faz referência à produção de Holly (1989) para distinguir vários tipos de diários, de acordo com a modalidade da narrativa empregada. Entre elas, a jornalística, a etnográfica, a reflexiva, a criativa ou poética. 
De outro modo, com o intuito de incentivar o uso sistemático da escrita como apoio à reflexão, o diário de registros propõe que o ato de registrar se realize a todo o momento, utilizando diferentes formas de escrita, além da escrita narrativa, que requer maior disponibilidade de tempo de distanciamento da experiência. A concepção freireana de escrita se associa ao pensamento de Mário Osório Marques (1997), para quem o ato de escrever é onde se inicia e conduz o ato de pesquisar, convidando-nos a "entender o ato de escrever como impulso vital por onde se libertam as forças do espírito e chegar a fazê-lo expressivo de minha singularidade criativa" (MARQUES, 1997, p.18).

Assim, a referência a um diário de registros (no lugar de diário de aula ou de pesquisa) tem a intenção de visibilizar a contribuição teórico-metodológica do legado freireano ${ }^{4}$, chamando atenção para sua compreensão acerca da função formativa do ato de registrar (FREITAS, 2010). Segundo Freire,

Precisamos exercitar nossa capacidade de observar, registrando o que
observamos. Mas registrar não se esgota no puro ato de fixar com
pormenores o observado tal qual para nós se deu. Significa também arriscar-
nos a fazer observações críticas e avaliativas a que não devemos, contudo,
emprestar ares de certeza (Freire, 1993, p.68).

$\mathrm{O}$ ato de registrar, como propõe Freire, envolve apontamentos diversos no exercício da escrita realizado em diferentes momentos, inclusive durante a própria ação, apoiando a memória para a reflexão posterior. Freire sugere, por exemplo, que educadores/as tenham a preocupação de ir "registrando estórias, retalhos de conversas, frases, expressões, que pudessem proporcionar análises semânticas, sintáticas, prosódicas do seu discurso" (FREIRE, 1992, p.72). Além desta diversidade da escrita, a perspectiva freireana apresenta uma concepção ampliada de registro, envolvendo outras modalidades para além da escrita, tais como imagens, pequenos bilhetes, materiais impressos, entre outros. Assim, ao reunir registros de natureza diversa, o diário constitui-se como um instrumento de ensino-pesquisa por meio do qual educador/a e educandos tomam para si o desafio da documentação da experiência, assumindo-a como objeto de investigação. Nesse processo, (trans)formam-se em "colecionadores/as do cotidiano", desenvolvendo práticas de registro e organizando-os, a fim de constituir a memória do trabalho realizado (FREITAS, 2014).

\footnotetext{
${ }^{4}$ Diferente do que indicam as normas ortográficas, a grafia empregada é a sugerida por Ana Maria Freire, mantendo inalterado o nome do autor.
} 
Desse modo, o diário de registros apoia a operacionalização do princípio do educar pela pesquisa (DEMO, 2003) no que diz respeito à superação de práticas de educação bancária, apresentando a aula reflexiva como alternativa à questão proposta por Pedro Demo acerca da necessidade de desfazer a imagem da aula copiada. Contrariamente à aula copiada, educar pela pesquisa propõe que a prática educativa se realize como um processo reconstrutivo permanente, que "inclui sempre a percepção emancipatória do sujeito que busca fazer e fazer-se oportunidade, à medida que começa e se reconstitui pelo questionamento sistemático da realidade” (op.cit., p.8). Para a superação da aula copiada, segundo o autor, faz-se necessário transformar a sala de aula em um lugar de trabalho conjunto, em que os educandos se movimentam, se organizam e se comunicam, participando de diferentes formas. Também se faz necessário que o/a educador/a se assuma como um profissional da educação pela pesquisa, transformandose em "orientador do processo de questionamento reconstrutivo no aluno" (op. cit., p.78), visto que é por meio do questionamento que o aprendiz exerce a posição de sujeito de sua aprendizagem.

É nesse sentido ampliado do educar pela pesquisa que se fundamenta o diário de registros, com o intuito de apoiar o desenvolvimento de práticas crítico-reflexivas, considerando que

A educação pela pesquisa pode ser construída de muitos modos diferentes. Não se constituindo em uma técnica linearizada, mas representando uma metodologia no sentido amplo, pode dar origem a diferentes modos de interpretação, sempre com base na capacidade criativa dos envolvidos (MORAES, 2012, p.102).

Além disso, neste percurso, o diálogo estabelecido entre Paulo Freire e diversos autores/as, tais como Maurice Tardif (2002), Marlene Grillo e Valderez Lima (2008); Boaventura de Sousa Santos (1997; 2009), Edgar Morin (1990), Carlos Rodrigues Brandão (1981; 2003), Donald Schön (2000), Isabel Alarcão (2001), entre outros/as, vem fortalecendo a compreensão acerca da educação como um ato político-complexo (FREITAS, 2004). A concepção da educação como um ato político-complexo diz respeito à compreensão de que a educação é um ato político porque orientado - de modo implícito ou explícito - pelas intencionalidades didático-pedagógicas que o constituem; e complexo porque, diferentemente de uma gestão empresarial, a gestão dos processos de ensinar e de aprender não se caracteriza pelo controle absoluto dos 


\section{AMBIENTE \& EDUCAÇÃO}

ISSN- 1413-8638

E-ISSN - 2238-5533

v. 22, n. 2, p. 6-27, 2017

resultados esperados. Dito de outra forma, a concepção da educação como um ato político-complexo diz respeito à compreensão de que a clareza das intencionalidades pedagógicas, associada à constante busca da coerência em sua operacionalização, é uma condição necessária, mas não suficiente para promover a aprendizagem. Requer levar em conta a natureza relacional dos processos de ensinar e de aprender, bem como os fundamentos interativos da docência (TARDIF; LESSARD, 2005), reconhecendo a multidimensionalidade de fatores que interferem nos resultados das práticas pedagógicas, para além das intencionalidades que as organizam.

Com base nesta compreensão, o diário de registros convida educadores/as e educandos ao questionamento, por meio do registro reflexivo, problematizando a passividade dos educandos e propondo sua participação para "fazer a aula", conforme propõe Rios (2008), ao afirmar que "a aula não é algo que se dá, mas algo que se faz, no trabalho conjunto de professores e alunos" (p.27). Ou seja, trata-se de assumir a pesquisa em sala de aula em seu princípio geral.

\section{A pesquisa em sala de aula pode ser compreendida como um movimento dialético, em espiral, que se inicia com o questionar os estados do ser, fazer e conhecer dos participantes, construindo-se a partir disso novos argumentos que possibilitam atingir novos patamares desse ser, fazer e conhecer, estágios esses então comunicados a todos os participantes do processo (MORAES; GALIAZZI; RAMOS, 2012, p.12).}

Assumida como atitude cotidiana, a dimensão investigativa da prática pedagógica se nutre do registro como fonte de reflexão (FREITAS 2010; 2014; 2017), sem desconsiderar a emoção mobilizada neste processo de (trans)formação docente. Em síntese, o educar pela pesquisa exercido com o apoio do diário de registros, apresenta-se como uma alternativa para transformar a tradição da aula copiada em aula refletida. Como começar? O que tem que escrever? Como é para ser feito? São questionamentos que emergem diante da exigência da escrita no diário. A problematização de uma visão prescritiva implícita em tais questionamentos pode ser um ponto de partida para desencadear o processo criativo de elaboração do diário, de modo a constituir-se como um instrumento de diálogo a ser exercido entre educador/a e educandos. O diálogo, freireanamente exercido, como "força que impulsiona o pensar crítico-problematizador em relação à condição humana no mundo" (ZITKOSKI, 2010, p.117), é o que fundamenta a mediação pedagógica no acompanhamento do processo de elaboração do diário. 
O diálogo problematizador, conceito estruturante do acompanhamento da elaboração do diário de registros, se realiza em função dos questionamentos oriundos de duas fontes de reflexão que se implicam mutuamente: o diálogo com a realidade social e o diálogo com a bibliografia de referência. Portanto, o diálogo problematizador precisa ser compreendido como um processo complexo, porque condicionado por uma multiplicidade de fatores que lhes são intrínsecos e extrínsecos, fazendo uso do diário de registros de modo a contribui para a ampliação da consciência das aprendizagens em processo e para o desenvolvimento da autoria de pensamento.

Neste sentido, a leitura dos diários dos educandos, exercida como mais uma forma de escuta, vem anunciando desafios à mediação docente no processo de sua elaboração, visto que, em muitas situações, a proposição do diário pode causar estranhamentos, mobilizando aspectos afetivo-relacionais que interferem em sua elaboração (SOLÉ, 2006). Entre outros, o medo é um aspecto afetivo-relacional mencionado de modo recorrente pelos educandos, sendo este um limitador da escrita no diário: o medo de errar, o medo de se expor, o medo do difícil, o medo de não ser capaz de corresponder às expectativas do/a professor/a, entre outros.

O percurso de ensino-pesquisa também tem mostrado que a proposição do diário, apesar de causar um estranhamento inicial pode transformar-se no decorrer da experiência, traduzindo-se em aprendizagens significativas. É preciso, portanto, compreendê-lo enquanto processo de (trans)formação docente e discente, ou seja, "é fazendo o diário que se aprende a fazê-lo", como revelam as vozes dos próprios educandos. Por isso, a mediação do educador é fundamental no processo de construção de compreensão/elaboração do diário, a fim de que os educandos possam usufruir os benefícios da utilização do diário como um instrumento de diálogo no acompanhamento de suas aprendizagens, proporcionando também o autoconhecimento. É nesta perspectiva que se apresentam a seguir os caminhos metodológicos da pesquisa realizada, cujos resultados indicam o "como fazer", buscando contribuir para vislumbrar a necessária rigorosidade metódica (FREIRE, 1995) a ser exercida no processo de elaboração do diário de registros.

\section{CAMINHOS METODOLÓGICOS}


Responder o questionamento sobre "como fazer" representou para as pesquisadoras, por algum tempo, uma espécie de tabu, em função do receio de reduzir a complexidade da experiência a um simples "passo a passo" a ser seguido. Todavia, a recorrência do questionamento foi se impondo como necessidade e anunciando a seguinte questão: como apresentar, de modo não prescritivo, uma orientação para que outros/as educadores/as possam usufruir dos benefícios do diário de registros como apoio à experiência de ensino-pesquisa?

Diante desta inquietação, entre as idas e vindas das participações em eventos acadêmicos ao longo dos últimos anos ${ }^{5}$, foram sendo produzidas sínteses parciais compartilhadas com outros/as educadores/as e pesquisadores/as, cujo diálogo contribuiu significativamente para a compreensão atual. Revisitar as produções acadêmicas anteriores foi um caminho metodológico para analisar a evolução da experiência com o diário de registros, realizada em diferentes contextos e com diversos sujeitos, tendo em vista sistematizar a compreensão que hoje se apresenta.

Foram revisitadas, conforme já referido, as produções de referência da formação acadêmica de cada uma das autoras: Freitas (2004); Machado (2012); Souza (2014). Também foram revisitadas outras produções acadêmicas que demarcam diferentes momentos da evolução desta proposição, levando em conta o modo de nomeá-la. Inicialmente, apoiando-se em Zabalza (2004) o instrumento utilizado foi referido como “diário de aula" (FREITAS, 2008; FREITAS, 2009), num segundo momento, com base em Barbosa (2010), preferiu-se utilizar "diário de pesquisa" (FREITAS, 2013; FREITAS， DIAS， SOUZA， 2013; FREITAS，MACHADO， 2014; FREITAS, FORSTER, 2016) e, finalmente, a produção mais recente assume o "diário de registros" (FREITAS, 2017) como alternativa para nomear a proposição deste instrumento de ensino-pesquisa, visibilizando a referência teórico-metodológica do legado freireano e destacando, conforme já referido, as peculiaridades que lhes são próprias.

Além disso, a documentação da experiência realizada pelas pesquisadoras a partir de seus próprios diários de registros, elaborados ao longo dos últimos anos, em

\footnotetext{
${ }^{5}$ A respeito de uma compreensão não prescritiva do "como fazer" destacam-se dois eventos cuja participação contribuiu para mais diretamente para vislumbrar os momentos e os questionamentos constitutivos do percurso de elaboração do diário: o VIII Colóquio Internacional Paulo Freire, organizado Centro Paulo Freire - Estudos e Pesquisas, em Recife - Campus da UFPE, de 19 a 21 de setembro de 2013; XVII Encontro Nacional de Didática e Prática de Ensino (ENDIPE), realizado na Universidade Federal do Ceará, de 11 a 14 de novembro de 2014.
} 
diferentes contextos de ensino, também foi uma referência para identificar especificidades, recorrências e convergências. Revisitar os próprios diários contribuiu, de modo complementar, mas não menos relevante, para identificar os momentos constitutivos do "como fazer", analisar as peculiaridades da emoção/reflexão mobilizadas no percurso e compreender a complexidade de (trans)formar a experiência docente em pesquisa.

\section{AFINAL, COMO FAZER?}

Inicialmente, merece reiterar a compreensão de que o foco no "como fazer" não se dissocia da intencionalidade pedagógica que o constitui, com base no pensamento freireano, de transformar a "cultura bancária" das relações de ensinar e de aprender, na perspectiva da construção da autonomia de educadores/as e educandos. Sendo assim, os resultados do processo de (trans)formação das relações de ensinar e de aprender precisam ser considerados em função de sua complexidade, ou seja, concebendo que não são imediatos e, portanto, representam um permanente desafio à autoria de educadores e educandos.

Todavia, os resultados da experiência das autoras com o diário de registros conforme já referido, corroboram com os estudos de vários/as pesquisadores/as (FAZENDA, 995; LÜDKE, 2001; DEMO, 2003, 2005; MORAES, LIMA: 2012) acerca de que o ensino, orientado pelo princípio educativo da pesquisa, transforma e redimensiona as relações de ensinar e de aprender. Compreende-se que o diário de registros constitui-se em um instrumento potencialmente (trans)formador das relações de ensinar e de aprender, na perspectiva da (trans)formação docente. Nesta compreensão reside a importância de sistematizar e compartilhar a orientação sobre o "como fazer".

A análise documental permitiu perceber que a compreensão e a significação do uso do diário não se realizam exclusivamente por uma exposição inicial do educador/a, mas se efetivam mediante o acompanhamento do percurso formativo, exercido por meio do diálogo. Por isso, vislumbrar o processo como um todo é fundamental para a realização deste acompanhamento, por parte do/a educador/a. É o que justifica a sistematização que se apresenta a seguir, organizada a partir da identificação de 
momentos e questionamentos que emergem no percurso da elaboração de diários de registros no âmbito do ensino.

Foram identificados quatro momentos que, conjuntamente, orientam o "como fazer" sem desconsiderar a complexidade do processo em que se problematizam as relações de ensinar e de aprender: o convite; os primeiros registros; a mediação do processo; e a avaliação da experiência. As ações do primeiro momento - o convite organizam-se a partir dos questionamentos relacionados ao planejamento inicial, cujas escolhas estão relacionadas a aspectos organizativos de ordem geral, tais como horário e tempo de duração do encontro, local e disponibilidade de espaço, número de pessoas e interesses do grupo, relação com temas e conteúdos específicos, entre outros. A apresentação da proposta na primeira aula de um semestre de estudos, no primeiro encontro de um curso de curta duração ou na primeira hora de uma oficina de formação realizada em um único encontro, é um dos aspectos da referida necessidade de contextualização do procedimento. As ações propostas precisam levar em conta a disponibilidade de recursos, ou seja, os cadernos a serem transformados em diários, e materiais de papelaria diversos, tais como cola, tesoura, revistas, papeis coloridos de diferentes texturas, etiquetas, adesivos, entre outros. O objetivo das ações propostas neste momento é o de criar condições para o estabelecimento de uma relação de proximidade entre o sujeito e o diário. Apesar da diversidade de contextos e propostas, este momento inicial tem como desafio comum motivar o grupo e cada um/a à elaboração do seu diário de registros. Por isso, a customização do diário é o ponto de partida para o convite, seguido de uma roda de diálogo, em que os participantes possam se apresentar a partir da capa dos diários, falando de si, de suas experiências e também de sua relação com a escrita, expectativas, etc.

As ações do segundo momento - os primeiros registros - dizem respeito ao movimento inicial de proposições para o registro, compreendido em suas diversas possibilidades e tendo em vista o desenvolvimento da prática de registrar. Para tanto, a orientação precisa ser clara, de modo a incentivar o ato de registrar, de modo sistemático e não esporádico, sem inicialmente preocupar-se com o tipo de registro. Neste sentido, é importante a proposição de que, a cada aula, além de seus apontamentos usuais, os educandos acrescentem pelo menos um registro que revele sua reflexão. Importante chamar atenção para as diversas formas de registro, não 
necessariamente por meio da escrita narrativa; pode ser um questionamento, um esquema, uma gravura, entre outros, que possam expressar sua reflexão naquele momento. A consigna diz respeito a um enunciado que desafia a atenção/observação durante a ação, a fim de que o registro deixe de ser eventual e passe a ser sistemático. Neste momento, o desafio à gestão do processo está na adequação da consígnia ao conteúdo e às necessidades de cada contexto, a fim de que os participantes atribuam sentido à continuidade da escrita, bem como, percebam sua necessidade. Desse modo, o diário de registros representa um convite à participação ativa, ampliando o diálogo entre educador/a e educandos por meio do desenvolvimento da atitude investigativa nas relações de ensinar e de aprender.

As ações do terceiro momento - a mediação do processo - dizem respeito à definição dos procedimentos de acompanhamento dos registros, por meio do diálogo problematizador, tendo em vista o desenvolvimento da escrita reflexiva, compreendida como aquela que se caracteriza como crítica e argumentativa. Neste sentido, a devolução comentada por parte do educador é fundamental para a significação do uso do diário. Na medida do possível, é importante que se realizem devoluções comentadas, em diferentes momentos de sua elaboração, seja no âmbito individual e/ou coletivo, de modo a caracterizá-lo como um instrumento de diálogo na relação entre educador e educando. Os registros de acompanhamento do processo contribuem para a compreensão do porquê e como fazer o diário, bem como para o desenvolvimento da autoconfiança em relação à elaboração criativa do modo próprio de registrar.

As ações do quarto momento - a avaliação da experiência - dizem respeito ao compartilhamento e reflexão sobre a experiência, bem como à análise das possibilidades de recriação da experiência com o diário, para além do contexto de sua aprendizagem. Neste último momento, as escolhas estão relacionadas à avaliação das repercussões da experiência em andamento, bem como à identificação de possibilidades de sua utilização em outros contextos. Relatos de experiência entre os educandos, mediante o compartilhamento em duplas, a organização de uma mostra de diários, entre outras ações, podem contribuir para incentivar novas proposições na autoria da escrita do diário e sua utilização em outros contextos. Importante referir que as ações relacionadas a este momento costumam emergir como resultado do processo, em função dos significados atribuídos. Muitas são as experiências em que, para além do 


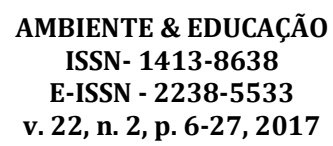

contexto de sua proposição, o uso do diário foi recriado em outros espaços, incluindo as relações informais. Assim, as repercussões são reveladoras dos significados atribuídos à experiência com o diário de registros no ensino; é o que justifica a proposição que hoje se apresenta.

Enfim, a sistematização apresentada destes quatro momentos para expressar o entendimento sobre o "como fazer" pretende constituir-se como uma orientação inicial, contribuindo para que educadores/as vislumbrem possibilidades de diversificação das ações, adequando-as às suas necessidades, sem perder de vista o foco no processo, levando em conta sua complexidade. Elucidar esta compreensão é relevante para orientar as escolhas para sua realização, em diferentes contextos, de modo a operacionalizar a intencionalidade didático-pedagógica que o constitui, conforme já referido, transformar a cultura bancária das relações de ensinar e de aprender, na perspectiva do desenvolvimento de práticas crítico-reflexivas. As escolhas feitas, bem como a permanente avaliação de suas repercussões, desenvolvem a autonomia e a autoria de educadores e educandos em relação ao uso do diário de registros, tendo em vista apoiar a formação de educadores/as pesquisadores/as. Espera-se que esta sistematização do "como fazer" não seja vista como prescrição, mas como referência para sua recriação.

\section{CONSIDERAÇÕES PARA SEGUIR A EXPERIÊNCIA DE ENSINO-PESQUISA}

Em síntese, o diário de registros apresenta-se como um procedimento utilizado com dupla finalidade: como um procedimento de ensino, o diário convida educandos e educadores/as ao diálogo e à reflexão sobre suas aprendizagens, mobilizando a atitude investigativa sobre o próprio percurso formativo e proporcionando a tomada de consciência de saberes e de ainda-não saberes; como um procedimento de pesquisa, o diário possibilita a documentação da experiência do ensino, fornecendo conteúdo para a reflexão sobre a prática, bem como para a pesquisa acadêmica. Todavia, apesar de serem identificados dois âmbitos distintos das contribuições do diário, seu potencial (trans)formador reside justamente na complementaridade com que as mudanças nas relações de ensinar e de aprender repercutem em ações de pesquisa e produção acadêmica por parte de educadores/as e educandos, assim como o inverso. 
Entre os desafios da proposição do diário de registros como um instrumento de ensino-pesquisa está a necessidade de problematizar - e transformar - a cultura bancária ainda presente também na visão dos educandos. Ao buscarem compreender o "como fazer" exclusivamente numa perspectiva técnica, submetem-se à condição de quem apenas cumpre tarefas, restringindo possibilidades de exercer sua autoria na elaboração do seu diário. Inversamente, a proposição do diário de registro como instrumento de ensino-pesquisa, pretende constituir-se como um convite aos educandos, desafiando-os a exercerem sua autoria de pensamento nas relações de ensinar e de aprender.

$\mathrm{Na}$ avaliação da experiência do diário de registros em diferentes contextos de ensino, também se evidencia a insatisfação de educandos que manifestam estranhamentos, incompreensões, medos e discordâncias. Diante desta diversidade dos percursos formativos, em que não se dissociam cognição e emoção, faz-se necessário o reconhecimento de que "aprendemos, ensinamos, conhecemos com o nosso corpo inteiro. Com os sentimentos, com as emoções, com os desejos, com os medos, com as dúvidas, com a paixão e também com a razão crítica. Jamais com esta apenas" (FREIRE, 1993, p.10). Requer compreender, sobretudo que "a experiência pedagógica é sempre um encontro e, como tal, um desequilíbrio entre os que dela participam, podendo tornar-se um momento de parceria ou de resistência (GRILLO; LIMA, 2008, p.53-54).

Sendo assim, faz-se necessária uma mediação pedagógica investigativa, capaz de aprender a conviver com as incertezas, de compreender a emoção como um elemento constitutivo da formação humana, desafiando-nos a aprender, na prática, a conviver com as incertezas (MORIN, 2000) e a reconhecer que o imprevisível é um componente intrínseco aos processos educativos. Reduzir o estranhamento inicial e maximizar as potencialidades do uso do diário de registros como apoio à aprendizagem representa tanto um desafio à experiência do ensino quanto um fecundo campo de investigação que merece ser perseguido, na perspectiva da construção da autonomia de educadores e educandos.

Por fim, é importante ainda considerar que a sistematização apresentada tem como referência um maior número de experiências em que o diário de registros caracterizou-se como uma elaboração pessoal, em espaços de educação formal (na escola e na universidade). Todavia, merecem ser destacadas outras possibilidades 
vislumbradas a partir das pesquisas que deram origem a esta proposição, tais como a elaboração de um diário coletivo ou sua recriação em espaços não escolares.

Retomando as considerações iniciais, o potencial (trans)formador da elaboração do diário de registros é um objeto de estudo que merece ser compartilhado. Espera-se que a sistematização apresentada contribua para orientar sua recriação em outros contextos, de modo a contribuir para maximizar o potencial emancipatório das relações de ensinar e de aprender nos processos de formação inicial e continuada de educadores/as.

Para tanto, faz-se necessário avançar em relação à criação de alternativas aos obstáculos - de toda ordem - que dificultam a concretização da utopia de que educadores/as e educandos se tornem pesquisadores nas relações de ensinar e de aprender. É o que justifica a continuidade da experiência de ensino-pesquisa. Trata-se de perseguir o inédito-viável no âmbito da (trans)formação docente, o que requer o trabalho coletivo de quem vive diariamente a luta na escola, na universidade e nas articulações que transformam sonhos em possibilidades.

\section{REFERÊNCIAS}

ALARCÃO, Isabel. (org.). Escola reflexiva e nova racionalidade. Porto Alegre: Artmed Editora, 2001.

BARBOSA, Joaquim Gonçalves; HESS, Remi. O diário de pesquisa: o estudante universitário e seu processo formativo. - Brasília: Liber Livro, 2010.

BRANDÃO, Carlos Rodrigues. O que é o método Paulo Freire. 1. ed. - São Paulo: Brasiliense, 1981. - (Coleção Primeiros Passos; vol. 38).

A pergunta a várias mãos: a experiência da pesquisa no trabalho do educador - São Paulo: Cortez, 2003. (Série saber com o outro; v. 1)

DEMO, Pedro. Educar pela pesquisa. 6. ed. Campinas, São Paulo: Editora Autores Associados, 2003, 6. ed. (Coleção Educação Contemporânea).

Pesquisa: princípio científico e educativo. 11. ed.- São Paulo: Cortez, 2005.

DICKMANN, Ivo. Pedagogia da (in)disciplina ambiental: desafios político-pedagógicos na formação de educadores ambientais no ensino superior. In: Rev. Eletrônica Mestr. Educ. Ambient. Rio Grande, Edição especial XVI Encontro Paranaense de Educação Ambiental, p. 55-70, set. 2017.

FAZENDA, Ivani Catarina Arantes. A pesquisa em educação e as transformações do conhecimento. Campinas, SP: Papirus, 1995. - (Coleção Práxis) 
FREIRE, Ana Maria Araújo. Utopia e democracia: os inéditos-viáveis na Educação Cidadã. In: AZEVEDO, José Clóvis et alii (org.). Utopia e democracia na Educação Cidadã. Porto Alegre: Editora da Universidade, UFRGS, p.13-21, 2000.

. Inédito viável. In: STRECK, Danilo; REDIN, Euclides; ZITKOSKI, Jaime José (orgs.). Dicionário Paulo Freire. - 2. ed., rev., amp., 1 reimp. Belo Horizonte: Autêntica Editora, p. 223 - 226, 2010.

FREIRE, Paulo. Pedagogia do Oprimido. $22^{\text {a }}$ ed. Rio de Janeiro: Paz e Terra, 1987.

Pedagogia da Esperança: um reencontro com a Pedagogia do oprimido. Rio de Janeiro: Paz e Terra, 1992.

Professora, sim; tia, não: cartas a quem ousa ensinar. São Paulo, Olho D’Agua, 1993.

À Sombra desta Mangueira. São Paulo: Olho d’Agua, 1995.

Pedagogia da Autonomia: Saberes necessários à prática educativa. São Paulo: Paz e Terra, 1996.

FREITAS, Ana Lúcia Souza de. FREITAS, Ana Lúcia Souza de. Pedagogia da Conscientização: um legado de Paulo Freire à formação de professores. Porto Alegre: EDIPUCRS, 2001.

Pedagogia do inédito-viável: contribuições da participação pesquisante em favor de uma política pública e inclusiva de formação com educadores e educadoras. Porto Alegre: PPGE/PUCRS, 2004. 989f. Tese (Doutorado em Educação). Pontifícia Universidade Católica do Rio Grande do Sul. Porto Alegre.

Diário de aula. In: GRILLO, Marlene Correro; GESSINGER, Rosana Maria; FREITAS, Ana Lúcia Souza de. LIMA, Valderez Marina do Rosário. A gestão da aula universitária na PUCRS. Porto Alegre/RS: EDIPUCRS, p.119-130, 2008.

Diário de Aula na Graduação: saberes e dilemas da experiência de ensinaraprender-pesquisar no ensino superior. In: ARAUJO, Maria Inês Oliveira; SOARES, Maria José Nascimento; ANDRADE, Djalma. Desafios da Formação de Professores para o Século XXI: a construção de um novo olhar sobre a prática docente. São Cristóvão: Editora UFS, p.111-125, 2009.

Registro. In: STRECK, Danilo; REDIN, Euclides; ZITKOSKI, Jaime José (orgs.). Dicionário Paulo Freire. - Belo Horizonte: Autêntica Editora, p. 355 - 356, 2010 .

Alunos felizes: uma utopia possível na aula de graduação. In: LUFT, Maria Hedi; FALKEMBACH, Elza Maria Fonseca (orgs). Freire na agenda da educação: educação ambiental e outros autores. - Ijuí: Ed. Unijuí, 2013 - 184 p., v:3. - (Coleção educação popular e movimentos sociais). 

2014, v.1.

Leituras de Paulo Freire: uma trilogia de referência. Passo Fundo, Méritos,

. Donald Schön e Paulo Freire: um diálogo fecundo na formação de uma professora-pesquisadora In: SHIGUNOV NETO, Alexandre; FORTUNATO, Ivan. 20 anos sem Donald Schön: o que aconteceu com o professor reflexivo? São Paulo: Edições Hipótese, p.116 a 137, 2017. Disponível em: $<$ https://drive.google.com/file/d/0B4VVtZy9vhzvY3lEaFJnTXEwSnM/view> Acesso: $16 / 10 / 2017$

FREITAS, Ana Lúcia Souza de; GESSINGER, Rosana Maria. O contrato didático e a avaliação. In: GRILLO, Marlene Correro; GESSINGER, Rosana Maria; FREITAS, Ana Lúcia Souza de. LIMA, Valderez Marina do Rosário. A gestão da aula universitária na PUCRS. Porto Alegre/RS: EDIPUCRS, 2008.

FREITAS, Ana Lúcia Souza de; DIAS, Marilena Iara; SOUZA, Micheli Silveira de. A formação com educadores/as na articulação universidade escola: a referência de Paulo Freire na experiência do PIBID. In: XV Fórum de Estudos: Leituras de Paulo Freire, FACCAT, Taquara, 2013, Anais. Disponível em: $<$ https://www2.faccat.br/portal/sites/default/files/freitas_dias_souza.pdf> Acesso: $16 / 10 / 2017$.

FREITAS, Ana Lúcia Souza de; MACHADO, Maria Elisabete. O diário de pesquisa como procedimento de ensinar e de aprender. Trabalho completo. In: Encontro Nacional de Didática e Prática de Ensino (ENDIPE), Fortaleza, 2014, Anais. Disponível em: <http://www.uece.br/endipe2014/index.php/2015-02-26-14-0914/search?author=808> Acesso: 16/10/2017.

FREITAS, Ana Lúcia Souza de; FORSTER, Mari Margarete dos Santos. Paulo Freire na formação de educadores: contribuições para o desenvolvimento de práticas críticoreflexivas. In: Dossiê Paulo Freire, a Prática Pedagógica e a Formação de Professores. Educar em Revista, Curitiba, Brasil, n. 61, p. 55-69, jul./set. 2016. Disponível em: <http://revistas.ufpr.br/educar/article/view/47206> Acesso: 16/10/2017.

GRILLO, Marlene Correro; LIMA, Valderez Marina do Rosário. A aula universitária como espaço de parceria. In: GRILLO, Marlene Correro; GESSINGER, Rosana Maria; FREITAS, Ana Lúcia Souza de. LIMA, Valderez Marina do Rosário. A gestão da aula universitária na PUCRS. Porto Alegre/RS: EDIPUCRS, 2008.

LÜDKE, Menga (org.). O professor e a pesquisa. Campinas, SP: Papirus, 2001. (Série Prática Pedagógica).

MACHADO, Maria Elisabete. Diálogos em roda: uma práxis pedagógica possível com a educação formal e não formal. Porto Alegre, 2012. 111f. Dissertação (Mestrado em Educação). Pontifícia Universidade Católica do Rio Grande do Sul. Porto Alegre. Disponível em: <http://tede2.pucrs.br/tede2/ handle/tede/3705> Acesso: 11/01/2017. 
MARQUES, Mário Osório. Escrever é preciso: o princípio da pesquisa. Ijuí: Ed. Unijuí, 1997 (Coleção Educação).

MIZUKAMI, Maria da Graça Nicoletti. Ensino: as abordagens do processo. (Coleção Temas Básicos do Ensino Contemporâneo). Rio de Janeiro: LTC, 2012.

MOITA, Maria da Conceição. Percursos de formação e de trans-formação. In: NÓVOA, António (org.). Vidas de Professores. Porto: Porto Editora, p.111-140, 1992.

MORAES, Roque. Educar pela pesquisa: exercício de aprender a aprender. In: MORAES, Roque; LIMA, Valderez Marina do Rosário. (orgs.). Pesquisa em sala de aula: tendências para educação em novos tempos. 3 ed. Porto Alegre: EDIPUCRS, 2012.

MORAES, Roque; LIMA, Valderez Marina do Rosário. (orgs.). Pesquisa em sala de aula: tendências para educação em novos tempos. 3 ed. Porto Alegre: EDIPUCRS, 2012.

MORAES, Roque; GALIAZZI, Maria do Carmo; RAMOS, Maurivan G. Pesquisa em sala de aula: fundamentos e pressupostos. In: MORAES, Roque; LIMA, Valderez Marina do Rosário (orgs.). Pesquisa em sala de aula: tendências para educação em novos tempos. 3 ed. Porto Alegre: EDIPUCRS, p. 11-20, 2012.

MORIN, Edgar. Ciência com consciência. Portugal: Publicações Europa-América Ltda., 1990.

RIOS, Terezinha Azerêdo. Compreender e Ensinar (Por uma docência da melhor qualidade) 3ed. São Paulo: Cortez Editora, 2008.

SANTOS, Boaventura de Sousa. Um discurso sobre as ciências. Portugal: Afrontamento, 1997, 9. ed.

- Para uma Pedagogia do Conflito. In: FREITAS, Ana Lúcia Souza de; MORAES, Salete Campos de (orgs.). Contra o desperdício da experiência: a Pedagogia do Conflito revisitada. Porto Alegre: Redes Editora, p. 15-40, 2009.

SARTORI, Jerônimo. Educação bancária. In: STRECK, Danilo; REDIN, Euclides; ZITKOSKI, Jaime José (orgs.). Dicionário Paulo Freire. - Belo Horizonte: Autêntica Editora, p.134-136, 2010.

SCHÖN, Donald A. Educando o profissional reflexivo: um novo design para o ensino e a aprendizagem. Tradução Roberto Cataldo Costa - Porto Alegre: Artes Médicas Sul, 2000 .

SOLÉ, Isabel. Disponibilidade para a aprendizagem e sentido da aprendizagem. In: COLL, César; et all. O construtivismo na sala de aula. São Paulo: Ática, 2006.

SOUZA, Micheli S. O diário de pesquisa na formação do educador pesquisador: a experiência do Pibid/Pedagogia, 2014. 59f. Trabalho de conclusão de curso (Graduação 
em Pedagogia) - Faculdade de Educação, Pontifícia Universidade Católica do Rio Grande do Sul. Porto Alegre.

TARDIF, Maurice. Saberes docentes e formação profissional. Petrópolis, RJ: Vozes, 2002.

TARDIF, Maurice \& LESSARD, Claude. Trabalho docente - elementos de uma teoria da docência como profissão de relações humanas. Petrópolis: Vozes, 2005.

ZABALZA, Miguel A. Diários de aula: um instrumento de pesquisa e desenvolvimento profissional. Tradução Ernani Rosa. Porto Alegre: Artmed, 2004

ZITKOSKI, Jaime. Diálogo/dialogicidade. In: STRECK, Danilo; REDIN, Euclides; ZITKOSKI, Jaime (orgs.). Dicionário Paulo Freire. Segunda edição revista e ampliada - Belo Horizonte: Autêntica Editora, p. 117-118, 2010. 